\begin{tabular}{ll|l}
\cline { 2 - 3 } & \multicolumn{2}{l}{ Intervent Neurol 2016;5:179-184 } \\
\cline { 2 - 3 } & $\begin{array}{l}\text { DOI: 10.1159/000447756 2016 S. Karger AG, Basel } \\
\text { Published online: July 15, 2016 }\end{array}$ & $\begin{array}{l}\text { 1664-9737/16/0054-0179\$39.50/0 } \\
\text { www.karger.com/ine }\end{array}$ \\
\hline
\end{tabular}

\title{
Functional Independence following Endovascular Treatment for Basilar Artery Occlusion despite Extensive Bilateral Pontine Infarcts on Diffusion-Weighted Imaging: Refuting a Self-Fulfilling Prophecy
}

\author{
Diogo C. Haussen Renato A.C. Oliveira Vikas Patel Raul G. Nogueira \\ Marcus Stroke \& Neuroscience Center, Grady Memorial Hospital, Emory University School \\ of Medicine, Atlanta, Ga., USA
}

\section{Key Words}

Stroke · Basilar artery · Cerebrovascular occlusion · Diffusion MR imaging · Pons · Patient outcome assessment

\begin{abstract}
Background and Purpose: Extensive brainstem diffusion-weighted imaging (DWI) hyperintensity has been associated with poor outcomes. We aim at documenting a series of patients with extensive DWI pontine lesions who achieved independence following endovascular therapy and aggressive medical therapy in the setting of posterior circulation basilar artery occlusion (BAO). Methods: This is a retrospective endovascular database review of a single-operator experience over a 9-year period for patients with (1) complete BAO, (2) extensive bilateral pontine DWI changes and (3) 90-day modified Rankin scale 0-2. Results: Three out of a total of 40 patients met the inclusion criteria. Case 1 was an 18-year-old male with National Institutes of Health Stroke Scale (NIHSS) 32 on admission, treated $25 \mathrm{~h}$ after symptom onset. Case 2 was a 56 -year-old male with NIHSS 19, treated $10 \mathrm{~h}$ after onset. Case 3 was a 73-year-old male with NIHSS 29, treated $6 \mathrm{~h}$ after onset. Full endovascular reperfusion was achieved in all 3 patients. A literature review identified 9 additional cases of extensive pontine DWI changes and good outcome. These patients were young (32 \pm 22 years), mostly males (69\%), presented with a relatively low posterior circulation Acute Stroke Prognosis Early CT Score $(6 \pm 1)$, were treated relatively late from last known normal (13 $\pm 10 \mathrm{~h})$ and were mostly (84\%) treated with endovascular intervention. Conclusion: Extensive bilateral pontine DWI lesions among patients with $\mathrm{BAO}$ are not an unequivocal indicator of poor prognosis. We advise strong caution when considering these findings in the treatment decision algorithm.
\end{abstract}




\section{Introduction}

Acute basilar artery occlusion (BAO) carries high morbidity and mortality [1]. Diffusionweighted imaging (DWI) has become the gold standard for the evaluation of the presence and extent of ischemic stroke, and it is particularly important for the evaluation of posterior fossa parenchyma in stroke. Patients presenting with extensive brainstem changes on pretreatment DWI are often excluded from endovascular therapy due to their predicted poor outcome [2]. We aim at documenting a series of patients with extensive bilateral DWI pontine lesions on post-treatment MRI who achieved functional independence following endovascular therapy and aggressive medical therapy in the setting of complete BAO.

\section{Methods}

This was a retrospective endovascular database review of a single-operator experience over a 9-year period performed to identify patients fulfilling the following criteria: (1) complete BAO, (2) extensive bilateral pontine DWI changes on post-treatment MRI and (3) 90-day modified Rankin scale (mRS) 0-2. Descriptive analysis of clinical, procedural and imaging findings is provided. BAO was classified into proximal (confluence of vertebral arteries to the takeoff of the anterior inferior cerebellar arteries), mid-basilar (from the anterior inferior cerebellar arteries to the origin of the superior cerebellar arteries) or distal (superior cerebellar arteries and distal) [3]. Stroke severity was assessed with the National Institutes of Health Stroke Scale (NIHSS). For the pediatric cases found in the literature, the Pediatric NIHSS was used [4]. This study was approved by the local institutional review boards.

A PubMed literature search was performed for the identification of all published reports that described patients with extensive bilateral pontine DWI hyperintensities and good clinical outcome from January 1996 to March 2016. Search terms included 'DWI', 'reversibility', 'basilar artery occlusion', 'thrombectomy', 'thrombolysis', 'pons', 'brainstem'. All articles in English encompassing retrospective or prospective studies were screened and subsequently evaluated for eligibility and inclusion.

\section{Results}

Three out of total 40 patients with acute ischemic stroke from BAO met our inclusion criteria. All patients had pre- or post-treatment MRI with DWI, had BAOs and were treated with mechanical thrombectomy resulting in complete (thrombolysis in cerebral infarction; TICI 3) reperfusion.

\section{Case 1}

Case 1 was an 18-year-old male without past medical history who developed acute paraparesis and right-hand clumsiness progressing to anarthria, obtundation and extensor posturing. Brain MRI demonstrated extensive areas of DWI restriction involving the bilateral rostral basis pontis (fig. 1a); the fluid-attenuated inversion recovery (FLAIR) sequence revealed very subtle hyperintensity in the pons. The preprocedural NIHSS was 24 , and the time from onset to puncture was $25 \mathrm{~h}$. Conventional angiography confirmed a basilar occlusion immediately past the origin of the anterior inferior cerebellar artery (fig. 1a). One pass of the Merci retriever partially recanalized with a residual right posterior cerebral artery occlusion treated with Penumbra 041 thromboaspiration resulting in full (TICI 3) reperfusion. Brain MRI performed 1 day after treatment showed reversibility of a large proportion of the DWI hyperintensity; however, significant FLAIR signal changes in the bilateral pons (fig. 1a) were still present. Workup was remarkable for a patent foramen ovale that was subsequently closed. At 90 days, NIHSS and mRS were 0. 
Haussen et al.: Functional Independence following Endovascular Treatment for BAO despite Extensive Bilateral Pontine Infarcts on DWI
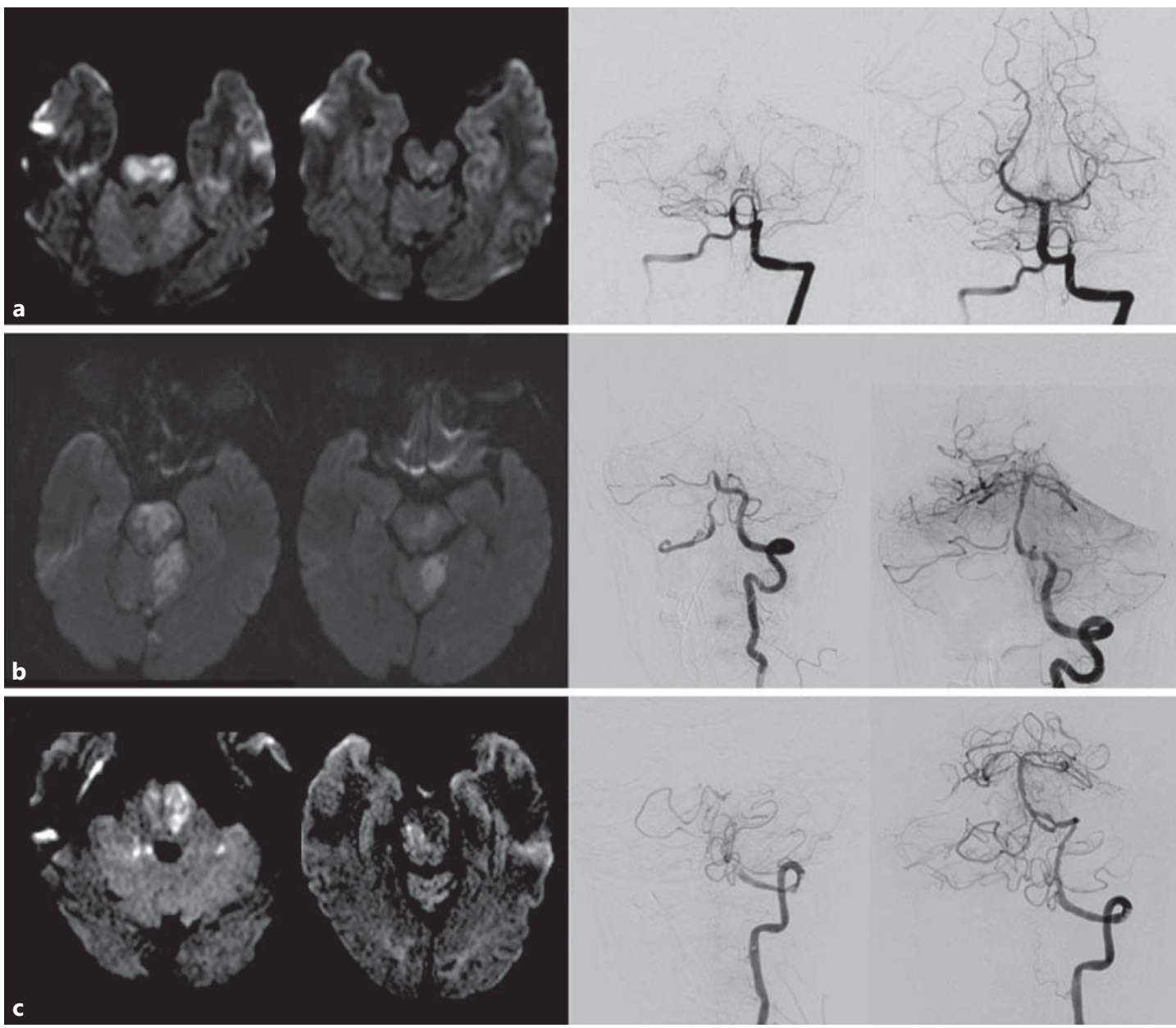

Fig. 1. MR and mechanical thrombectomy imaging of the reported cases. a Case 1. b Case 2. c Case 3. MRI DWI showing different pontine levels (left) and pre- and postfrontal angiography (right).

\section{Case 2}

Case 2 was a 56-year-old male patient with a history of hypertension, alcohol and tobacco abuse who presented with acute anarthria, right facial droop and right-sided weakness at an outside hospital. NIHSS was 19, CT angiography showed a BAO and the time interval from onset to puncture was $10 \mathrm{~h}$. Angiography confirmed a BAO immediately past the origin of the anterior inferior cerebellar artery (fig. 1b). One pass of stent retriever thrombectomy led to reperfusion and exposed an underlying atherosclerotic plaque with $70 \%$ stenosis. Balloonmounted stenting was performed, leading to complete reperfusion (TICI 3). Brain DWI after $24 \mathrm{~h}$ showed multifocal acute infarctions involving the bilateral cerebellum, right middle cerebellar peduncle, central pons (left greater than right), right pontomesencephalic and right midbrain, as well as the splenium of the right corpus callosum (fig. 1b); FLAIR revealed hyperintensity within the aforementioned pontine lesion. The patient was discharged from the hospital after 7 days with a NIHSS of 4. His NHISS was 2 and mRS was 1 at 90 days of follow-up.

Case 3

Case 3 was a 73-year-old male with a past medical history of hypertension who had a wake-up stroke last seen normal $6 \mathrm{~h}$ before. He was found lethargic, anarthric, with left hemi- 
Haussen et al.: Functional Independence following Endovascular Treatment for BAO despite Extensive Bilateral Pontine Infarcts on DWI

Table 1. Summary of the reported cases of BAO with extensive DWI pontine hyperintensities and good outcome

\begin{tabular}{|c|c|c|c|c|c|c|c|c|c|c|c|c|}
\hline First author [ref.] & Year & Case & $\begin{array}{l}\text { Age, } \\
\text { years }\end{array}$ & Sex & NIHSS & $\begin{array}{l}\text { pc- } \\
\text { ASPECTS }\end{array}$ & $\begin{array}{l}\text { Occlusion } \\
\text { site }\end{array}$ & Etiology & Therapy & $\begin{array}{l}\text { Time from } \\
\text { onset to } \\
\text { therapy, } \mathrm{h}\end{array}$ & TICI & $\begin{array}{l}90- \\
\text { day } \\
\text { mRS }\end{array}$ \\
\hline Current study & 2016 & 1 & 18 & M & 32 & 5 & Mid & PFO & IAT & 25 & TICI 3 & 0 \\
\hline Current study & 2016 & 2 & 56 & M & 19 & 4 & Mid & ICAD & IAT & 10 & TICI 3 & 1 \\
\hline Current study & 2016 & 3 & 73 & $\mathrm{~F}$ & 29 & 4 & Proximal & ICAD & IAT & 6 & TICI 3 & 2 \\
\hline Ladner [5] & 2014 & 4 & 5 & M & $22^{\mathrm{a}}$ & 6 & Mid & Dissection & IAT & 9 & TICI $2 \mathrm{~b}$ & 0 \\
\hline \multirow[t]{2}{*}{ Bodey [6] } & 2014 & 5 & 10 & M & $27^{\mathrm{a}}$ & 7 & Distal & Dissection & IAT & 36 & - & $3^{\mathrm{b}}$ \\
\hline & & 6 & 6 & M & $28^{\mathrm{a}}$ & 8 & - & Dissection & IAT & - & - & $0^{\mathrm{b}}$ \\
\hline Yoo [7] & 2010 & 7 & 67 & $\mathrm{~F}$ & 31 & 8 & Mid & - & IAT & 8 & - & 0 \\
\hline \multirow[t]{3}{*}{ Samaniego [8] } & 2009 & 8 & 32 & M & 25 & 8 & - & Dissection & IV tPA & - & - & 0 \\
\hline & & 9 & 16 & M & 35 & 6 & - & Dissection & IAT & 20 & - & 0 \\
\hline & & 10 & 30 & $\mathrm{~F}$ & - & 6 & - & - & IV tPA & - & - & 2 \\
\hline Alderazi [10] & 2014 & 11 & 41 & M & 12 & 6 & Proximal & PFO & IAT & 5.5 & TICI 3 & 0 \\
\hline \multirow[t]{2}{*}{ Tomycz [9] } & 2008 & 12 & 46 & M & - & 5 & Mid & $\begin{array}{l}\text { Athero- } \\
\text { thrombotic }\end{array}$ & IAT & 11 & TIMI 2 & 1 \\
\hline & & 13 & 27 & F & - & 7 & Proximal & Dissection & IAT & 7 & TIMI 2 & 1 \\
\hline
\end{tabular}

PFO = Patent foramen ovale; pc-ASPECTS = posterior circulation Acute Stroke Prognosis Early CT Score; ICAD = intracranial atherosclerotic disease; IV tPA = intravenous tissue plasminogen activator; IAT = intra-arterial therapy; TIMI = thrombolysis in myocardial ischemia. ${ }^{\mathrm{a}}$ Pediatric NIHSS. ${ }^{\mathrm{b}}$ mRS for children.

plegia and was taken to an outside hospital and was intubated. NIHSS was 29, and CT angiography revealed intracranial left vertebral artery occlusion with extension into the basilar artery. Upon arrival, head CT showed a hyperdense basilar artery and patchy hypodense areas in the cerebellum. The time from last normal to puncture was $6 \mathrm{~h}$. Angiography confirmed a left vertebral V4 occlusion immediately after the origin of the posterior inferior cerebellar artery (fig. 1c), and stent retriever thrombectomy with local thromboaspiration led to recanalization, revealing high-grade mid-basilar stenosis. This was followed by balloon angioplasty of the basilar and thromboaspiration of the left posterior cerebellar artery. NIHSS at $24 \mathrm{~h}$ was 4. DWI of the brain 5 days after thrombectomy revealed bilateral DWI hyperintensity (fig. 1c) and correspondent hyperintensity on FLAIR. The hospital course was complicated and prolonged by aspiration pneumonia. The patient was discharged from the hospital after 3 weeks to a long-term acute care facility still on mechanical ventilation via tracheostomy. However, clinical evaluation at 90 days demonstrated nearly no residual deficits with a NIHSS $=1$ and $m R S=2$.

The literature review has identified additional 9 cases of extensive pontine DWI changes and good outcome (table 1) [5-10]. The patients were young (32 \pm 22 years), mostly males (69\%), presented with a low posterior circulation Acute Stroke Prognosis Early CT Score $(6 \pm 1)$, were treated relatively late from last known normal $(13 \pm 10 \mathrm{~h})$ and were mostly $(84 \%)$ treated with endovascular intervention.

\section{Discussion}

The present series corroborate the previous suggestion that extensive DWI changes do not constitute an absolute marker of poor outcome and should not be used to automatically exclude patients from reperfusion therapies.

Many studies had shown that early DWI lesions on the pontine region represent an independent predictor of poor outcomes [2,11-13]. Results from a study of 29 patients revealed 
that a higher brain stem 22-point semiquantitative DWI lesion score was the only independent baseline predictor for clinical outcome [2]. An association between $>10$-point semiquantitative DWI score at baseline and poorer outcome or death ( $\mathrm{mRS} \geq 3$ ) has been reported in another study of 16 individuals [14]. A 31-patient study of patients with BAO indicated that more extensive DWI brainstem load on a 12-point semi-quantitative scoring system was highly predictive of poor clinical outcome [15].

Our findings reinforce previously published reports and indicate that extensive pontine DWI changes do not constitute an unequivocal sign of poor outcome [5-9]. The pooled documented cases of good outcome despite extensive pontine DWI changes indicate that this phenomenon occurred more often in young patients who were typically treated endovascularly and was observed even with a late presentation from last known normal to puncture.

Brainstem DWI hyperintensity can undergo diffusion normalization following successful treatment of BAO $[7,16]$. DWI reversibility has been reported to be commonly transient, has been demonstrated not to correlate with early reperfusion and not to independently predict good outcomes [17]. It is unclear if DWI lesions of the brain stem behave differently from anterior circulation infarcts [14]. However, the findings reported in this series indicate that regardless of its radiological reversibility, DWI changes are not a definite indicator of poor prognosis. The reported cases highlight the potential role of reperfusion among patients with extensive involvement of basilar artery.

\section{Conclusion}

Extensive bilateral pontine DWI lesions among patients with $\mathrm{BAO}$ are not an unequivocal indicator of poor prognosis. This occurrence has been reported in relatively young patients more commonly reperfused endovascularly. We advise strong caution when considering these findings in the treatment decision algorithm.

\section{Disclosure Statement}

D.C.H., R.A.C.O., and V.P. have no conflicts of interest to disclose. R.G.N. has the following disclosures: Stryker Neurovascular (Trevo-2 Trial PI, DAWN Trial PI), Covidien (SWIFT and SWIFT-PRIME Steering Committee, STAR Trial Core Lab) and Penumbra (3-D Separator Trial Executive Committee).

\section{References}

1 Smith WS: Intra-arterial thrombolytic therapy for acute basilar occlusion: pro. Stroke 2007;38(2 suppl):701703.

2 Cho TH, Nighoghossian N, Tahon F, Nemoz C, Hermier M, Salkine F, Derex L, Trouillas P, Froment JC, Turjman F: Brain stem diffusion-weighted imaging lesion score: a potential marker of outcome in acute basilar artery occlusion. AJNR Am J Neuroradiol 2009;30:194-198.

3 Archer CR, Horenstein S: Basilar artery occlusion: clinical and radiological correlation. Stroke 1977;8:383390.

4 Ichord RN, Bastian R, Abraham L, Askalan R, Benedict S, Bernard TJ, Beslow L, Deveber G, Dowling M, Friedman N, Fullerton H, Jordan L, Kan L, Kirton A, Amlie-Lefond C, Licht D, Lo W, McClure C, Pavlakis S, Smith SE, Tan M, Kasner S, Jawad AF: Interrater reliability of the Pediatric National Institutes of Health Stroke Scale (PedNIHSS) in a multicenter study. Stroke 2011;42:613-617.

5 Ladner TR, He L, Jordan LC, Cooper C, Froehler MT, Mocco J: Mechanical thrombectomy for acute stroke in childhood: how much does restricted diffusion matter? BMJ Case Rep 2014;2014:pii:bcr2014011465.

6 Bodey C, Goddard T, Patankar T, Childs AM, Ferrie C, McCullagh H, Pysden K: Experience of mechanical thrombectomy for paediatric arterial ischaemic stroke. Eur J Paediatr Neurol 2014;18:730-735. 
Haussen et al.: Functional Independence following Endovascular Treatment for BAO despite Extensive Bilateral Pontine Infarcts on DWI

7 Yoo AJ, Hakimelahi R, Rost NS, Schaefer PW, Hirsch JA, Gonzalez RG, Rabinov JD: Diffusion weighted imaging reversibility in the brainstem following successful recanalization of acute basilar artery occlusion. J Neurointerv Surg 2010;2:195-197.

8 Samaniego EA, Lansberg MG, DeGeorgia M, Venkatasubramanian C, Wijman CA: Favorable outcome from a locked-in state despite extensive pontine infarction by MRI. Neurocrit Care 2009;11:369-371.

9 Tomycz ND, Holm MB, Horowitz MB, Wechsler LR, Raina K, Gupta R, Jovin TG: Extensive brainstem ischemia on neuroimaging does not preclude meaningful recovery from locked-in syndrome: two cases of endovascularly managed basilar thrombosis. J Neuroimaging 2008;18:15-17.

10 Alderazi YJ AL, Sumida A, Ortiz GA: Early diffusion changes may not predict poor outcome in basilar occlusion: a case report. Stroke Intervent 2014, Epub ahead of print.

11 Nagel S, Herweh C, Kohrmann M, Huttner HB, Poli S, Hartmann M, Hahnel S, Steiner T, Ringleb P, Hacke W: MRI in patients with acute basilar artery occlusion - DWI lesion scoring is an independent predictor of outcome. Int J Stroke 2012;7:282-288.

12 Karameshev A, Arnold M, Schroth G, Kappeler L, Stein P, Gralla J, Brekenfeld C, Findling O, Mono ML, De Marchis GM, Fischer U, Mattle HP, Nedeltchev K, El-Koussy M: Diffusion-weighted MRI helps predict outcome in basilar artery occlusion patients treated with intra-arterial thrombolysis. Cerebrovasc Dis 2011;32:393400.

13 Yoon W, Kim SK, Heo TW, Baek BH, Lee YY, Kang HK: Predictors of good outcome after stent-retriever thrombectomy in acute basilar artery occlusion. Stroke 2015;46:2972-2975.

14 Renard D, Landragin N, Robinson A, Brunel H, Bonafe A, Heroum C, Milhaud C: MRI-based score for acute basilar artery thrombosis. Cerebrov Dis 2008;25:511-516.

15 Mourand I, Machi P, Nogue E, Arquizan C, Costalat V, Picot MC, Bonafe A, Milhaud D: Diffusion-weighted imaging score of the brain stem: a predictor of outcome in acute basilar artery occlusion treated with the Solitaire FR device. AJNR Am J Neuroradiol 2014;35:1117-1123.

16 Suzuki S, Kidwell CS, Starkman S, Saver JL, Duckwiler G, Vinuela F, Ovbiagele B: Use of multimodal MRI and novel endovascular therapies in a patient ineligible for intravenous tissue plasminogen activator. Stroke 2005;36:e77-e79.

17 Inoue M, Mlynash M, Christensen S, Wheeler HM, Straka M, Tipirneni A, Kemp SM, Zaharchuk G, Olivot JM, Bammer R, Lansberg MG, Albers GW; DEFUSE 2 Investigators: Early diffusion-weighted imaging reversal after endovascular reperfusion is typically transient in patients imaged 3 to 6 hours after onset. Stroke 2014;45: 1024-1028. 